\title{
Downregulation of Polo-like kinase-1 (PLK-1) expression is associated with poor clinical outcome in uveal melanoma patients
}

\author{
Tomasz Berus ${ }^{1}$, Anna Markiewicz², Katarzyna Kobylinska ${ }^{3}$, Przemyslaw Biecek², \\ Jolanta Orlowska-Heitzman ${ }^{4}$, Bozena Romanowska-Dixon², Piotr Donizy ${ }^{5}$
}

\author{
${ }^{1}$ Department of Ophthalmology, $4^{\text {th }}$ Military Clinical Hospital with Polyclinic, Wroclaw, Poland \\ ${ }^{2}$ Department of Ophthalmology and Ocular Oncology, the Jagiellonian University, Medical College, \\ Krakow, Poland \\ ${ }^{3}$ Faculty of Mathematics, Informatics and Mechanics University of Warsaw, Warsaw, Poland \\ ${ }^{4}$ Department of Pathomorphology, the Jagiellonian University, Medical College, Krakow, Poland \\ ${ }^{5}$ Department of Pathomorphology and Oncological Cytology, Wroclaw Medical University, \\ Wroclaw, Poland
}

\begin{abstract}
Introduction. Uveal melanoma (UM) is the most common primary eye tumour in adults. Distant metastases are seen in $50 \%$ of cases regardless of treatment, which contributes to high mortality rates. Polo-like kinase-1 (PLK-1) is a protein regulator of mitotic entry and cytokinesis. Increased PLK-1 expression has been shown in different tumours, which makes its inhibition a potential treatment target. To date, no study has been published to discuss the prognostic role of PLK-1 expression in patients with uveal melanoma.

Material and methods. We assessed by immunohistochemistry PLK-1 expression in uveal melanoma cells collected in 158 patients treated by primary enucleation. We determined the correlation between PLK-1 levels evaluated by the immunoreactivity scale (IRS) method and detailed clinical as well as histological parameters. Additionally, we determined the association between PLK-1 expression levels and long-term prognosis.

Results. Elevated PLK-1 expression in tumour cells, defined as IRS >2, was observed in 70\% (111/158) of cases, whereas low expression or no expression was seen in the remaining 30\% (47/158) of patients. There was a significant correlation between low PLK-1 expression and a higher clinical tumour stage ( $\mathrm{pT}, \mathrm{p}=0.04)$ as well as a higher AJCC prognostic stage group $(\mathrm{p}=0.037)$. We observed an inverse correlation between PLK-1 expression and tumour cell pigment content $(\mathrm{p}=0.0019)$. There was no correlation between PLK-1 expression and other histological parameters such as mitotic rate or histological subtype. The Kaplan-Meier's analysis demonstrated that low PLK-1 expression was associated with significantly reduced overall survival $(p=0.0058)$. A similar trend, albeit not significant, was observed for disease-free survival $(\mathrm{p}=0.088)$.

Conclusions. Downregulated PLK-1 expression is a negative prognostic factor in uveal melanoma. It warrants further, multicentre research on prognostic role of PLK-1 expression and possibility of PLK-1 inhibition in uveal melanoma. (Folia Histochemica et Cytobiologica 2020, Vol. 58, No. 2, 108-116)
\end{abstract}

Key words: uveal melanoma; polo-like kinase-1; prognostic factor; IHC

Correspondence address: Tomasz Berus, MD

Department of Ophthalmology

4th Military Clinical Hospital with Polyclinic,

Weigla 5, 50-981 Wroclaw, Poland

e-mail: tberus@op.pl

\section{Introduction}

Uveal melanoma (UM) is the most common primary eye tumour in adults. The incidence in the general population is below 10 cases per million population per year [1]. We have previously discussed epidemi- 
ology and prognostic factors in uveal melanoma in a comprehensive review [2]. Depending on the clinical course of disease, chances for vision preservation and patient expectations, primary tumours can be effectively treated with brachytherapy, proton beam irradiation, transpupillary thermotherapy, local resection, endoresection, or enucleation. Regardless of the selected treatment modality, almost $50 \%$ of affected patients develop distant metastases, which contributes to very high mortality rates [2]. Conventional chemotherapy, isolated hepatic perfusion, immunoembolisation, surgery and checkpoint inhibitors have very limited efficacy in metastatic UM with the median overall survival (OS) of 1.07 years (range: $0.59-2.50$ years) across all treatment modalities [3].

Polo-like kinase-1 (PLK-1) is a serine/threonine-protein kinase consisting of a highly conservative $\mathrm{N}$-terminal kinase domain (KD) of 252 amino-acids and a C-terminal Polo-box domain (PBD), that is, two conserved polo-box regions of 30 amino-acids connected via a short linker. An interaction with peptides phosphorylated by other kinases involved in the cell cycle changes the PBD conformation. Acting like a clip, it docks PLK-1 at its accurately selected target site during the appropriate stage of cell division $[4,5]$, whereby PLK- 1 becomes a master regulator of mitosis and cytokinesis [6].

PLK-1 has been implicated in Cdk1-cyclin B activation at mitotic entry, centrosome maturation, bipolar spindle formation, activation of anaphase promoting complex/cyclosome (APC/C), accumulation of spindle assembly checkpoint (SAC) proteins at kinetochores, sister chromatid separation, as well as cytokinesis [7-9]. Furthermore, PLK-1 has recently been shown to play a role in microtubule dynamics, DNA replication, chromosome dynamics, p53 regulation, and recovery from the G2 DNA-damage checkpoint [10].

PLK-1 overexpression has been demonstrated in a number of human tumours, where it often correlates with increased cellular proliferation and poor prognosis [11-18], e.g. in skin melanoma [19, 20]. Therefore, it is currently considered a prooncogenic factor, which exerts its effect by affecting cell cycle checkpoints and causing genetic instability. As such, it is the target of cancer therapies [21], which seems potentially plausible also in UM [22].

The aim of this study was to assess the PLK-1 expression in UM as well as its correlation with detailed clinical and pathological parameters, and long-term survival.

\section{Material and methods}

Patients. The study group consisted of 158 patients with uveal melanoma treated by primary enucleation at the De- partment of Ophthalmology and Ocular Oncology, Medical College, Jagiellonian University in Krakow, Poland, diagnosed in 2002-2011. Patients were enrolled in the study based on the availability of their medical records and tissue specimens, which included paraffin blocks and histological slides. Comprehensive clinical data was retrieved from the archived medical records, and details of diagnostic and therapeutic procedures performed were sourced out from the Ocular Oncology Outpatient Clinic, University Hospital, Krakow, Poland. The study was reviewed and approved by the ethical committees of the Jagiellonian University, Krakow, Poland (decision no. 122.6120.58.216), and the Wroclaw Medical University, Wroclaw, Poland (decision no. KB-500/2017).

Records were reviewed for clinical and pathological data including age, sex, affected eye, largest basal diameter and thickness of the tumour, tumour staging ( $\mathrm{pT}$ and AJCC prognostic stage group), tumour location relative to the equator, ciliary body involvement, clinical tumour pigmentation and shape, concomitant glaucoma and/or retinal detachment, histological subtype, scleral and/or optic nerve infiltration, as well as tumour necrosis. Additionally, detailed histological parameters, such as mitotic rate, presence of tumour-infiltrating lymphocytes (TILs), nuclear pseudoinclusions (NPIs), intranuclear grooves, multinucleated giant cells and haemorrhage, as well as tumour cell pigmentation level were considered. The largest basal diameter and thickness of the tumour were described in line with the guidelines of the American Joint Committee on Cancer (AJCC) [23].

Immunohistochemistry. Paraffin blocks with tissues of 158 primary uveal melanomas were cut with a microtome to prepare $4 \mu \mathrm{m}$-thick sections which were subsequently mounted on sialinized slides (Agilent DAKO, Santa Clara, CA, USA). The slides then underwent automated dewaxing, rehydration and heat-induced epitope retrieval with EnVision Target Retrieval Solution (Agilent DAKO) for $30 \mathrm{~min}$ at $97^{\circ} \mathrm{C}$ in PT Link Pre-Treatment Module for Tissue Specimens (DAKO). Automated immunohistochemical staining with anti-PLK-1 (rabbit monoclonal antibody, 208G4; \#4513; dilution 1:100; Cell Signalling Technology, Danvers, MA, USA) was performed in Autostainer Link 48 (DAKO) and Liquid Permanent Red (Agilent DAKO) was utilized as a detection system. Human colorectal adenocarcinoma was stained as positive control. Negative controls were processed using FLEX Rabbit Negative Control, Ready-to-Use (Agilent DAKO) in place of the primary antibody.

Evaluation of PLK-1 expression. The expression of PLK-1 in UM cells (Fig. 1) was determined using the semi-quantitative method. The two IHC reaction parameters used were the percentage of cells with a positive cytoplasmic reaction (the percentage of reactive tissue) and the intensity of cytoplasmic PLK-1 reaction. The Remmele and Stegner semiquantitative immunoreactive score (IRS) was used to compute 

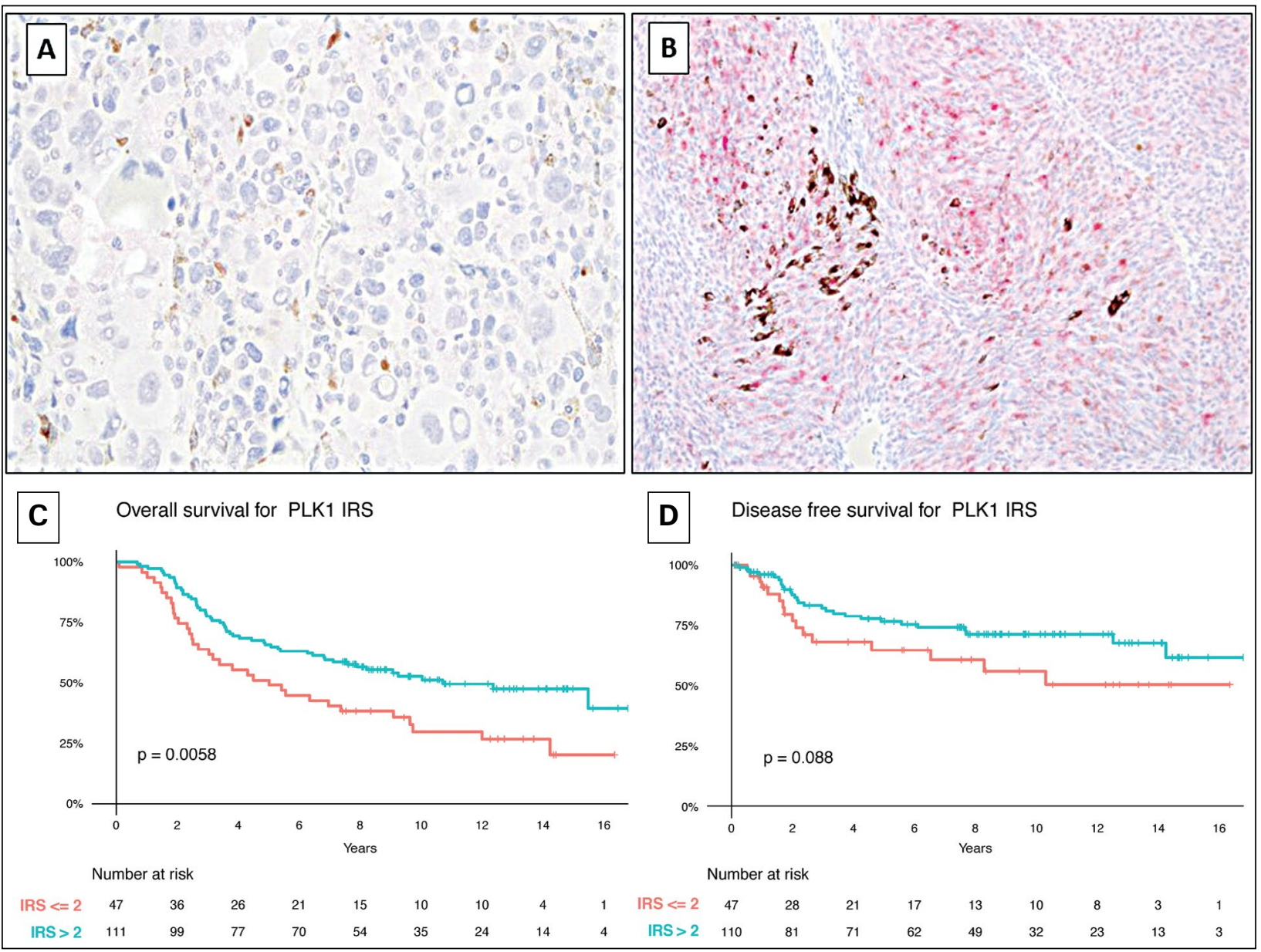

Figure 1. PLK-1 expression in uveal melanoma. A. Lack of PLK-1 immunoreactivity in neoplastic cells (400×). B. Enhanced expression of PLK-1 in uveal melanoma cells $(200 \times)$. C. Kaplan-Meier analysis of the prognostic impact of PLK-1 expression in uveal melanoma patients. Downregulation of PLK-1 expression was significantly correlated with reduced overall survival $(p=0.0058)$. D. A similar trend as in $(C)$, albeit not significant, was observed for disease-free survival $(p=0.088)(D)$.

the above parameters [24]. In the IRS, the percentage of reactive cells scores $0-4$ points and staining intensity scores $0-3$ points. The ultimate IRS is a product of multiplication of the above parameters, ranging between 0 and 12 points.

Tumoural pigmentation was assessed using a three-step scale: 0 - lack of melanin or melanin was present in $<10 \%$ of melanoma cells; 1 (low): melanin was present in 11-50\% of melanoma cells; 2 (high): melanin was present in 51-100\% melanoma cells.

Statistical analysis. Statistical analysis was performed using the R language [25] and the survminer tool [26]. For the purposes of correlation analysis, we assumed a dichotomous division of PLK-1 expression into low and high corresponding to semiquantitative IRS of $\leq 2$ and $>2$, respectively. In order to determine the overall survival (OS) and disease-free survival (DFS), Kaplan-Meier curves and the log-rank test were used; all analyses were carried out using the survival package for $\mathrm{R}[25,26]$. In order to determine the correlations between the PLK-1 expression and continuous variables, the Wilcoxon two-sample test was used. The correlations between PLK-1 expression and binary variables were determined using the Fisher's exact test while the correlations with other categorical variables were determined using the chi-square test. The $\mathrm{p}$ value below 0.05 was considered significant for all comparisons.

\section{Results}

\section{PLK-1 immunoreactivity in uveal melanoma cells}

High PLK-1 expression, defined as IRS $>2$, was observed in $70 \%(111 / 158)$ of specimens, whereas low expression or no expression was seen in the remaining 30\% (47/158) of specimens, including undetectable PLK-1 expression in $3.8 \%(6 / 158)$ of specimens (Fig. 1A-B). The mean IRS for PLK-1 expression in tumour cells was 4 (median: 4). 


\section{Correlations of PLK-1 expression with clinical parameters}

There was a significant inverse correlation between PLK-1 expression and the basal tumour diameter $(\mathrm{p}=0.044)$. Similarly, there was a significant correlation between low PLK-1 expression and higher clinical tumour stage ( $\mathrm{pT}, \mathrm{p}=0.040$ ) as well as AJCC prognostic stage group $(\mathrm{p}=0.037)$. Interestingly, high PLK-1 expression was associated with more advanced age of patients $(\mathrm{p}=0.0019)$, whereas low PLK-1 expression was associated with a higher incidence of retinal detachment secondary to UM $(\mathrm{p}=0.0076)$ (Table 1).

\section{Correlations of PLK-1 expression with histological parameters}

There was an inverse correlation between PLK-1 expression and tumour cell pigment content $(\mathrm{p}=0.0019)$ and a positive correlation between PLK-1 expression and the presence of nuclear grooves $(\mathrm{p}=0.017)$. On the other hand, low PLK-1 expression significantly correlated with the presence of nuclear pseudoinclusions (NPIs) $(\mathrm{p}=0.0071)$. There was no significant correlation between PLK-1 expression and other histological parameters such as mitotic rate or histological subtype (Table 2).

The effect of PLK-1 expression on long-term survival The Kaplan-Meier's analysis demonstrated that low PLK-1 expression was associated with significantly reduced overall survival ( $\mathrm{p}=0.0058)$. A similar trend, albeit not significant, was observed for disease-free survival $(\mathrm{p}=0.088)($ Fig. 1C-D).

\section{Discussion}

PLK-1 is a protein with important roles in the regulation of the cell cycle. It is physiologically strongly expressed in tissues undergoing intensive proliferation, such as testes, thymus, and spleen, or during proliferative events such as in developing embryos etc. [27]. Hence, the question follows whether high PLK-1 expression in tumour cells is associated with oncogenesis or intense cell proliferation. Over 25 years of PLK-1-related research, a number of papers have been published to characterise its mechanism of action, both in the cell cycle and in cellular response to DNA damage [28-30].

PLK-1 and the $\mathrm{p} 53$ tumour suppressor protein are closely related in an inhibitory feedback loop, which is the fundamental mechanism whereby PLK-1 participates in oncogenesis [28]. High PLK-1 expression leading to cell cycle acceleration was demonstrated in tumour cells lacking functional p53. However, overexpression of PLK-1 inhibits the effect of p53. As a result, the cell is incapable of apoptosis in response to DNA damage and continues to function with increasing genomic instability and aneuploidy [29, 31-36]. PLK-1 depletion breaks the vicious circle restoring the p53 function. Importantly, it also triggers tumour cell apoptosis whilst preserving normal cells [37-39]. Apart from interaction with p53, PLK-1 may regulate tumorigenesis by modulating Myc stability [40, 41] and affecting PTEN [42] as well as other tumour suppressors [43].

This provides the theoretical basis for the research of PLK-1 inhibitors, which block kinase domain or PBD [4]. One of them, volasertib, was granted a Breakthrough Therapy designation by the FDA [44] and reached Phase III of clinical trials in patients aged 65 years and above with previously untreated acute myeloid leukaemia [45, 46]. Nevertheless, despite expectations based on preclinical study findings, no significant clinical success of PLK-1 inhibitors has been reported to date [47]. The search for more selective inhibitors is ongoing, as kinases, including those of the PLK family, can often exert opposing effects on tumour development [27, 47]. Using PLK-1 inhibitors in combination therapy as agents reducing cancer resistance to other therapies, seems promising at the moment [46, 47].

As pharmaceutical companies and researchers have been trying to find a therapeutic use of PLK-1 inhibitors, the kinase has also sparked significant controversies [48]. While PLK-1 overexpression is linked to uncontrolled cell proliferation and impaired response to DNA damage, its low expression impairs cell cycle processes, such as spindle assembly or centrosome maturation, leading to tumour progression [30]. Recent studies in mice not only confirmed these findings, but also demonstrated the potential of PLK-1 as a tumour suppressor [49-52]. This inhibition effect is possible in interaction with specific oncogenes (such as K-Ras, Her2 or APC $^{\text {min }}$ ) and may be caused by upor down-regulation of PLK-1 expression [43], both of which can induce genetic instability and aneuploidy. Hence, the outcomes are likely determined by other factors rather than a stand-alone PLK-1 expression level, such as oncogenesis, tumour progression or potential protective/repair mechanisms.

De Cárcer [43] analysed data from the Cancer Genome Atlas (TGCA) [53] and the Kaplan Meier Plotter database [54, 55], demonstrating that PLK-1 overexpression may lead to different outcomes depending on tumour type. For example, it was linked to shorter overall survival (OS) in patients with lung, bladder, and kidney clear cell carcinoma, whereas in patients with thymoma, lung squamous cell carcino- 
Table 1. Summary statistics for relation between expression of PLK-1 in uveal melanoma cells and clinical parameters

\begin{tabular}{|c|c|c|c|}
\hline \multirow[t]{2}{*}{ Clinical parameters } & \multicolumn{3}{|c|}{ PLK-1 IRS } \\
\hline & Low $\leq 2$ (No. 47) & High $>2($ No. 111) & $p$ value \\
\hline Age in years $(18-86)^{a}$ & $63(58-72)$ & $59(51-64)$ & 0.0019 \\
\hline Gender $^{c}$ & & & 1.0 \\
\hline Female & $24(51 \%)$ & $58(52 \%)$ & \\
\hline Male & $23(49 \%)$ & $53(48 \%)$ & \\
\hline Side $^{c}$ & & & 0.86 \\
\hline Right & $22(47 \%)$ & $54(49 \%)$ & \\
\hline Left & $25(53 \%)$ & $57(51 \%)$ & \\
\hline Largest basal tumour diameter (by AJCC) ${ }^{b}$ & & & 0.044 \\
\hline$>9-12 \mathrm{~mm}$ & $2(4 \%)$ & $11(10 \%)$ & \\
\hline$>12-15 \mathrm{~mm}$ & $3(6 \%)$ & $24(22 \%)$ & \\
\hline$>15-18 \mathrm{~mm}$ & $13(28 \%)$ & $26(23 \%)$ & \\
\hline$>18 \mathrm{~mm}$ & $29(62 \%)$ & $50(45 \%)$ & \\
\hline Greatest tumour height (by AJCC) $)^{b}$ & & & 0.75 \\
\hline$\leq 3 \mathrm{~mm}$ & $0(0 \%)$ & $1(1 \%)$ & \\
\hline$>3-6 \mathrm{~mm}$ & $2(4 \%)$ & $12(11 \%)$ & \\
\hline$>6-9 \mathrm{~mm}$ & $13(28 \%)$ & $28(25 \%)$ & \\
\hline$>9-12 \mathrm{~mm}$ & $16(34 \%)$ & $40(36 \%)$ & \\
\hline$>12-15 \mathrm{~mm}$ & $12(26 \%)$ & $24(22 \%)$ & \\
\hline$>15 \mathrm{~mm}$ & $4(9 \%)$ & $6(5 \%)$ & \\
\hline Primary tumour $(\mathbf{p T})^{b}$ & & & 0.040 \\
\hline 2 & $1(2 \%)$ & $12(11 \%)$ & \\
\hline 3 & $11(23 \%)$ & $39(35 \%)$ & \\
\hline 4 & $35(74 \%)$ & $60(54 \%)$ & \\
\hline Stage $^{b}$ & & & 0.037 \\
\hline IIA & $0(0 \%)$ & $10(9 \%)$ & \\
\hline IIB & $10(21 \%)$ & $33(30 \%)$ & \\
\hline IIIA & $15(32 \%)$ & $37(33 \%)$ & \\
\hline IIIB & $16(34 \%)$ & $26(23 \%)$ & \\
\hline IIIC & $6(13 \%)$ & $5(5 \%)$ & \\
\hline Localization $^{\text {b }}$ & & & 0.53 \\
\hline In front of the equator & $39(55 \%)$ & $32(49 \%)$ & \\
\hline Equator & $11(15 \%)$ & $8(12 \%)$ & \\
\hline Behind the equator & $21(30 \%)$ & $25(38 \%)$ & \\
\hline Ciliary body involvement ${ }^{\mathrm{c}}$ & & & 0.41 \\
\hline Ciliary body not involved & $53(63 \%)$ & $56(70 \%)$ & \\
\hline Ciliary body involved & $31(37 \%)$ & $24(30 \%)$ & \\
\hline Degree of pigmentation ${ }^{b}$ & & & 0.21 \\
\hline Amelanotic & $4(10 \%)$ & $22(21 \%)$ & \\
\hline Mild pigmentation & $16(38 \%)$ & $42(39 \%)$ & \\
\hline Intense pigmentation & $22(52 \%)$ & $43(40 \%)$ & \\
\hline Shape $^{\mathrm{c}}$ & & & 0.73 \\
\hline Dome shape & $23(50 \%)$ & $60(55 \%)$ & \\
\hline Mushroom shape & $23(50 \%)$ & $50(45 \%)$ & \\
\hline Retinal detachment $^{\mathrm{c}}$ & & & 0.0076 \\
\hline No RD & $3(6 \%)$ & $28(25 \%)$ & \\
\hline Coexistence of RD & $44(94 \%)$ & $83(75 \%)$ & \\
\hline Glaucoma $^{c}$ & & & 0.46 \\
\hline No glaucoma & $39(83 \%)$ & $96(87 \%)$ & \\
\hline Coexistence of glaucoma & $8(17 \%)$ & $14(13 \%)$ & \\
\hline
\end{tabular}

${ }^{a} p$ value of Wilcoxon two sample test; ${ }^{b} p$ value of chi $^{2}$ test; ${ }^{c} p$ value of Fisher's exact test. Statistically significant results $(P<0.05)$ are shown in bold text. 
Table 2. Summary statistics for relation between expression of PLK-1 in uveal melanoma cells and histopathological parameters

\begin{tabular}{|c|c|c|c|}
\hline \multirow[t]{2}{*}{ Histopathological parameters } & \multicolumn{3}{|c|}{ PLK-1 IRS } \\
\hline & Low $\leq 2($ No. 47) & High $>2$ (No. 111) & $p$ value \\
\hline Histologic subtype $\mathrm{e}^{\mathrm{a}}$ & & & 0.46 \\
\hline Spindle cell melanoma & $6(13 \%)$ & $23(21 \%)$ & \\
\hline Mixed cell melanoma & $34(72 \%)$ & $75(68 \%)$ & \\
\hline Epithelioid cell melanoma & $7(15 \%)$ & $13(12 \%)$ & \\
\hline Mitotic rate ${ }^{b}$ & & & 0.47 \\
\hline $0-4$ & $32(70 \%)$ & $70(63 \%)$ & \\
\hline $5-31$ & $14(30 \%)$ & $41(37 \%)$ & \\
\hline Scleral infiltration $^{\mathrm{b}}$ & & & 0.16 \\
\hline None or intrascleral infiltration & $44(94 \%)$ & $109(98 \%)$ & \\
\hline Full-thickness infiltration & $3(6 \%)$ & $2(2 \%)$ & \\
\hline Invasion of the optic nerve ${ }^{a}$ & & & 0.59 \\
\hline No invasion & $38(81 \%)$ & $91(82 \%)$ & \\
\hline Optic nerve head invasion & $9(19 \%)$ & $17(15 \%)$ & \\
\hline Optic nerve invasion & $0(0 \%)$ & $3(3 \%)$ & \\
\hline Necrosis $^{b}$ & & & 0.60 \\
\hline No necrosis & $39(85 \%)$ & $92(88 \%)$ & \\
\hline Necrosis present & $7(15 \%)$ & $12(12 \%)$ & \\
\hline Marked pleomorphism ${ }^{\mathrm{b}}$ & & & 0.57 \\
\hline No marked pleomorphism & $41(87 \%)$ & $101(91 \%)$ & \\
\hline Marked pleomorphism present & $6(13 \%)$ & $10(9 \%)$ & \\
\hline TILs $^{\mathrm{b}}$ & & & 0.44 \\
\hline No TILs & $43(91 \%)$ & $96(86 \%)$ & \\
\hline TILs present & $4(9 \%)$ & $15(14 \%)$ & \\
\hline Multinucleated giant cells ${ }^{\mathrm{b}}$ & & & 0.54 \\
\hline No multinucleated giant cells & $34(72 \%)$ & $86(77 \%)$ & \\
\hline Multinucleated giant cells present & $13(28 \%)$ & $25(23 \%)$ & \\
\hline NPIs $^{\mathrm{b}}$ & & & 0.0071 \\
\hline No NPIs & $21(45 \%)$ & $76(68 \%)$ & \\
\hline NPIs present & $26(55 \%)$ & $35(32 \%)$ & \\
\hline Intranuclear grooves $^{\mathrm{b}}$ & & & 0.017 \\
\hline No intranuclear grooves & $43(91 \%)$ & $82(74 \%)$ & \\
\hline Intranuclear grooves present & $4(9 \%)$ & $29(26 \%)$ & \\
\hline Haemorrhage $^{\mathrm{b}}$ & & & 0.082 \\
\hline No haemorrhage & $33(70 \%)$ & $93(84 \%)$ & \\
\hline Haemorrhage present & $14(30 \%)$ & $18(16 \%)$ & \\
\hline Pigmentationa $^{\mathrm{a}}$ & & & 0.0019 \\
\hline Lack of melanin & $2(4 \%)$ & $12(11 \%)$ & \\
\hline Low pigmentation & $18(38 \%)$ & $68(61 \%)$ & \\
\hline High pigmentation & $27(57 \%)$ & $31(28 \%)$ & \\
\hline
\end{tabular}

${ }^{\mathrm{a}} p$ value of $\mathrm{chi}^{2}$ test; ${ }^{\mathrm{b}} p$ value of Fisher's exact test. Statistically significant results $(P<0.05)$ are shown in bold font. 
ma or rectal adenocarcinoma, higher PLK-1 levels seemed to be associated with significantly longer OS [43]. Interestingly, PLK-1 overexpression did not affect survival prognosis in patients with ovarian cancer, stomach adenocarcinoma and cervical squamous cell carcinoma [43]. Nevertheless, the effect of PLK-1 expression on long-term follow-up in patients with uveal melanoma was not assessed in that study.

In our research, contrary to most mentioned above reports, indicating PLK-1 as a prognostic factor for poor prognosis, we observed high PLK-1 expression in smaller UM tumours and in patients with lower clinical tumour stage (pT and AJCC). Furthermore, the Kaplan-Meier survival analysis demonstrated that high PLK-1 expression was associated with significantly shorter overall survival, with a similar trend in disease-free survival.

PLK- 1 is one of the 50 most overexpressed genes of primary cutaneous melanoma $(\mathrm{CM})$ and its metastases as compared with melanocytic nevi [56]. The expression of PLK-1 is dynamically regulated during CM cell cycle and is vital for cell survival. The level of PLK-1 varies with tumour thickness and has prognostic value for CM. High PLK-1 expression was significantly correlated with unfavourable clinical outcome [20]. Also for thin melanomas $(<0.75 \mathrm{~mm})$, which should have an excellent prognosis, high expression of PLK-1 is a reliable marker for identifying patients at high risk of metastasis [19]. Kinetochore complex component (NDC80), a downstream effector in the PLK-1 signalling pathways, involved in the occurrence of many tumours and highly expressed in a variety of cancer types, is also associated with poor overall survival in metastatic $\mathrm{CM}$ $[57,58]$. Therefore, determining PLK-1 expression, in addition to the Breslow thickness, can help identify patients with aggressive tumours.

Specific inhibition of PLK-1 using the commercially available inhibitor BI 2536 leads to a dose- and time-dependent decrease in CM cell viability and induction of apoptosis [56]. Moreover it shows an additive effect with simultaneous inhibition of the mitogen-activated protein kinase (MAPK) signalling pathway or inhibition of mitogen-activated protein kinase/extracellular signal-regulated kinase (MEK). Therefore, combination of MAPK/MEK and PLK-1 inhibition could be a potentially attractive therapeutic strategy in CM [56, 59-61].

Unfortunately, many differences between CM and UM mean that other therapeutic strategies need to be sought in uveal melanoma. One of proposed explanations is ocular immune privilege, which may likely alter signalling pathways in UM compared to skin melanoma [62]. The studies assessing biological drugs in UM have not shown good results to date
[62]. Although PLK-1 inhibitors appear promising in oncology, and PLK-1 has been identified as one of UM-specific therapeutic targets [22], our results support the need for multicentre studies on prognostic significance of PLK-1 expression in uveal melanoma and in vitro studies to determine the effect of inducing or inhibiting PLK-1 expression in UM cells.

\section{Funding}

A statutory subsidy by the Polish Ministry of Science and Higher Education as part of grants ST.B130.18. 030 and SUB.B130.20.022 (record numbers in the Simple system). PBi was financially supported by the Polish National Science Centre under Opus Grant number 2017/27/B/ST6/0130.

\section{References}

1. Singh AD, Turell ME, Topham AK. Uveal melanoma: trends in incidence, treatment, and survival. Ophthalmology. 2011; 118(9): 1881-1885, doi: 10.1016/j.ophtha.2011.01.040, indexed in Pubmed: 21704381.

2. Berus T, Halon A, Markiewicz A, et al. Clinical, Histopathological and Cytogenetic Prognosticators in Uveal Melanoma - A Comprehensive Review. Anticancer Res. 2017; 37(12): 6541-6549, doi: 10.21873/anticanres.12110, indexed in Pubmed: 29187428.

3. Rantala ES, Hernberg M, Kivelä TT. Overall survival after treatment for metastatic uveal melanoma: a systematic review and meta-analysis. Melanoma Res. 2019; 29(6): 561 568, doi: 10.1097/CMR.0000000000000575, indexed in Pubmed: 30664106.

4. Elia AEH, Rellos P, Haire LF, et al. The molecular basis for phosphodependent substrate targeting and regulation of Plks by the Polo-box domain. Cell. 2003; 115(1): 83-95, doi: 10.1016/s0092-8674(03)00725-6, indexed in Pubmed: 14532005 .

5. Archambault V, Lépine G, Kachaner D. Understanding the Polo Kinase machine. Oncogene. 2015; 34(37): 4799-4807, doi: 10.1038/onc.2014.451, indexed in Pubmed: 25619835.

6. Combes G, Alharbi I, Braga LG, et al. Playing polo during mitosis: PLK1 takes the lead. Oncogene. 2017; 36(34): 4819-4827, doi: 10.1038/onc.2017.113, indexed in Pubmed: 28436952

7. Petronczki M, Lénárt P, Peters JM. Polo on the Rise-from Mitotic Entry to Cytokinesis with Plk1. Dev Cell. 2008; 14(5): 646-659, doi: 10.1016/j.devcel.2008.04.014, indexed in Pubmed: 18477449.

8. Lénárt P, Petronczki M, Steegmaier M, et al. The small-molecule inhibitor BI 2536 reveals novel insights into mitotic roles of polo-like kinase 1. Curr Biol. 2007; 17(4): 304-315, doi: 10.1016/j.cub.2006.12.046, indexed in Pubmed: 17291761.

9. Barr FA, Silljé HHW, Nigg EA. Polo-like kinases and the orchestration of cell division. Nat Rev Mol Cell Biol. 2004; 5(6): 429-440, doi: 10.1038/nrm1401, indexed in Pubmed: 15173822 .

10. Liu XS, Song B, Liu X. The substrates of Plk1, beyond the functions in mitosis. Protein Cell. 2010; 1(11): 999-1010, doi: 10.1007/s13238-010-0131-x, indexed in Pubmed: 21153517.

11. Wolf G, Hildenbrand R, Schwar C, et al. Polo-like kinase: a novel marker of proliferation: Correlation with estrogen-receptor expression in human breast cancer. Pathology - Research and Practice. 2000; 196(11): 753-759, doi: 10.1016/ s0344-0338(00)80107-7. 
12. Donizy P, Halon A, Surowiak P, et al. Augmented expression of Polo-like kinase 1 is a strong predictor of shorter cancer-specific overall survival in early stage breast cancer at 15-year follow-up. Oncol Lett. 2016; 12(3): 1667-1674, doi: 10.3892/ol.2016.4890, indexed in Pubmed: 27602103.

13. Tokumitsu Y, Mori M, Tanaka S, et al. Prognostic significance of polo-like kinase expression in esophageal carcinoma. Int J Oncol. 1999; 15(4): 687-692, doi: 10.3892/ijo.15.4.687, indexed in Pubmed: 10493949.

14. Wolf G, Elez R, Doermer A, et al. Prognostic significance of polo-like kinase (PLK) expression in non-small cell lung cancer. Oncogene. 1997; 14(5): 543-549, doi: 10.1038/ sj.onc.1200862, indexed in Pubmed: 9053852.

15. Takai N, Miyazaki T, Fujisawa K, et al. Expression of polo-like kinase in ovarian cancer is associated with histological grade and clinical stage. Cancer Lett. 2001; 164(1): 41-49, doi: 10.1016/s0304-3835(00)00703-5, indexed in Pubmed: 11166914

16. Macmillan JC, Hudson JW, Bull S, et al. Comparative expression of the mitotic regulators SAK and PLK in colorectal cancer. Ann Surg Oncol. 2001; 8(9): 729-740, doi: 10.1007/ s10434-001-0729-6, indexed in Pubmed: 11597015.

17. Cheng MW, Wang BC, Weng ZQ, et al. Clinicopathological significance of Polo-like kinase 1 (PLK1) expression in human malignant glioma. Acta Histochem. 2012; 114(5): 503-509, doi: 10.1016/j.acthis.2011.09.004, indexed in Pubmed: 22000864.

18. Lin P, Wen DY, Dang YW, et al. Comprehensive and Integrative Analysis Reveals the Diagnostic, Clinicopathological and Prognostic Significance of Polo-Like Kinase 1 in Hepatocellular Carcinoma. Cell Physiol Biochem. 2018; 47(3): 925-947, doi: 10.1159/000490135, indexed in Pubmed: 29843122.

19. Kneisel L, Strebhardt K, Bernd A, et al. Expression of polo-like kinase (PLK1) in thin melanomas: a novel marker of metastatic disease. J Cutan Pathol. 2002; 29(6): 354-358, doi: 10.1034/j.1600-0560.2002.290605.x, indexed in Pubmed: 12135466.

20. Strebhardt, K. Prognostic Value of Pololike Kinase Expression in Melanomas. JAMA: The Journal of the American Medical Association. 2000; 283(4): 479-480, doi: 10.1001/ jama.283.4.479.

21. Otto T, Sicinski P. Cell cycle proteins as promising targets in cancer therapy. Nat Rev Cancer. 2017; 17(2): 93-115, doi: 10.1038/nrc.2016.138, indexed in Pubmed: 28127048

22. Bailey FP, Clarke K, Kalirai H, et al. Kinome-wide transcriptional profiling of uveal melanoma reveals new vulnerabilities to targeted therapeutics. Pigment Cell Melanoma Res. 2018; 31(2): 253-266, doi: 10.1111/pcmr.12650, indexed in Pubmed: 28972303.

23. Grossniklaus HE, Finger PT, Harbour JW, et al. Protocol for the Examination of Specimens From Patients With Uveal Melanoma, https://documents.cap.org/protocols/ cp-uveal-melanoma-17protocol-4000.pdf (2017, accessed 12 March 2020).

24. Remmele W, Stegner HE. [Recommendation for uniform definition of an immunoreactive score (IRS) for immunohistochemical estrogen receptor detection (ER-ICA) in breast cancer tissue]. Pathologe. 1987; 8(3): 138-140, indexed in Pubmed: 3303008.

25. R Core Team. R: A language and environment for statistical computing. R Foundation for Statistical Computing, Vienna, Austria, https://www.r-project.org/ (2019, accessed 12 March 2020).

26. Kassambara A, Kosinski M, Biecek P. survminer: Drawing Survival Curves using 'ggplot2'. R package version 0.4.6., https://cran.r-project.org/package $=$ survminer $(2019$, accessed 12 March 2020).

27. Strebhardt K. Multifaceted polo-like kinases: drug targets and antitargets for cancer therapy. Nat Rev Drug Discov. 2010; 9(8): 643-660, doi: 10.1038/nrd3184, indexed in Pubmed: 20671765.

28. Eckerdt F, Yuan J, Strebhardt K. Polo-like kinases and oncogenesis. Oncogene. 2005; 24(2): 267-276, doi: 10.1038/ sj.onc.1208273, indexed in Pubmed: 15640842.

29. Takai N, Hamanaka R, Yoshimatsu J, et al. Polo-like kinases (Plks) and cancer. Oncogene. 2005; 24(2): 287-291, doi: 10.1038/sj.onc.1208272, indexed in Pubmed: 15640844.

30. Weng Ng WT, Shin JS, Roberts TL, et al. Molecular interactions of polo-like kinase 1 in human cancers. J Clin Pathol. 2016; 69(7): 557-562, doi: 10.1136/jclinpath-2016-203656, indexed in Pubmed: 26941182.

31. Liu XS, Li H, Song B, et al. Polo-like kinase 1 phosphorylation of G2 and S-phase-expressed 1 protein is essential for p53 inactivation during $\mathrm{G} 2$ checkpoint recovery. EMBO Rep. 2010; 11(8): 626-632, doi: 10.1038/embor.2010.90, indexed in Pubmed: 20577264.

32. Yang X, Li H, Zhou Z, et al. Plk1-mediated phosphorylation of Topors regulates p53 stability. J Biol Chem. 2009; 284(28): 18588-18592, doi: 10.1074/jbc.C109.001560, indexed in Pubmed: 19473992.

33. Chen J, Dai Gu, Wang YQ, et al. Polo-like kinase 1 regulates mitotic arrest after UV irradiation through dephosphorylation of $\mathrm{p} 53$ and inducing $\mathrm{p} 53$ degradation. FEBS Lett. 2006; 580(15): 3624-3630, doi: 10.1016/j.febslet.2006.05.047, indexed in Pubmed: 16753148.

34. Dias SS, Hogan C, Ochocka AM, et al. Polo-like kinase-1 phosphorylates MDM2 at Ser260 and stimulates MDM2-mediated p53 turnover. FEBS Lett. 2009; 583(22): 3543-3548, doi: 10.1016/j.febslet.2009.09.057, indexed in Pubmed: 19833129

35. Ando K, Ozaki T, Yamamoto $\mathrm{H}$, et al. Polo-like kinase 1 (Plk1) inhibits 553 function by physical interaction and phosphorylation. J Biol Chem. 2004; 279(24): 25549-25561, doi: 10.1074/jbc.M314182200, indexed in Pubmed: 15024021.

36. McKenzie L, King S, Marcar L, et al. p53-dependent repression of polo-like kinase-1 (PLK1). Cell Cycle. 2010; 9(20): 4200-4212, doi: 10.4161/cc.9.20.13532, indexed in Pubmed: 20962589.

37. Liu X, Erikson RL. Polo-like kinase (Plk)1 depletion induces apoptosis in cancer cells. Proc Natl Acad Sci U S A. 2003; 100(10): 5789-5794, doi: 10.1073/pnas.1031523100, indexed in Pubmed: 12732729.

38. Liu X, Lei M, Erikson RL. Normal cells, but not cancer cells, survive severe Plk1 depletion. Mol Cell Biol. 2006; 26(6): 2093-2108, doi: 10.1128/MCB.26.6.2093-2108.2006, indexed in Pubmed: 16507989.

39. Guan R, Tapang P, Leverson JD, et al. Small interfering RNA-mediated Polo-like kinase 1 depletion preferentially reduces the survival of p53-defective, oncogenic transformed cells and inhibits tumor growth in animals. Cancer Res. 2005; 65(7): 2698-2704, doi: 10.1158/0008-5472.CAN-04-2131, indexed in Pubmed: 15805268.

40. Ren Y, Bi C, Zhao X, et al. PLK1 stabilizes a MYC-dependent kinase network in aggressive B cell lymphomas. J Clin Invest. 2018; 128(12): 5517-5530, doi: 10.1172/JCI122533, indexed in Pubmed: 30260324.

41. Xiao D, Yue M, Su H, et al. Polo-like Kinase-1 Regulates Myc Stabilization and Activates a Feedforward Circuit Promoting Tumor Cell Survival. Mol Cell. 2016; 64(3): 493-506, doi: 10.1016/j.molcel.2016.09.016, indexed in Pubmed: 27773673. 
42. Choi BH, Pagano M, Dai W. Plk1 protein phosphorylates phosphatase and tensin homolog (PTEN) and regulates its mitotic activity during the cell cycle. J Biol Chem. 2014; 289(20): 14066-14074, doi: 10.1074/jbc.M114.558155, indexed in Pubmed: 24706748.

43. Cárcer Gde. The Mitotic Cancer Target Polo-Like Kinase 1: Oncogene or Tumor Suppressor? Genes. 2019; 10(3): 208, doi: 10.3390/genes10030208.

44. Boehringer Ingelheim's investigational volasertib receives FDA Breakthrough Therapy designation, https://www. boehringer-ingelheim.us/press-release/boehringer-ingelheims-investigational-volasertib-receives-fda-breakthrough-therapy (accessed 1 February 2020).

45. Volasertib in Combination With Low-dose Cytarabine in Patients Aged 65 Years and Above With Previously Untreated Acute Myeloid Leukaemia, Who Are Ineligible for Intensive Remission Induction Therapy (POLO-AML-2), https://clinicaltrials.gov/ct2/show/NCT01721876?term = polo-aml-2\&rank $=1$ (accessed 1 February 2020).

46. Van den Bossche J, Lardon F, Deschoolmeester V, et al. Spotlight on Volasertib: Preclinical and Clinical Evaluation of a Promising Plk1 Inhibitor. Med Res Rev. 2016; 36(4): 749-786, doi: 10.1002/med.21392, indexed in Pubmed: 27140825.

47. Gutteridge RE, Ndiaye MA, Liu X, et al. Plk1 Inhibitors in Cancer Therapy: From Laboratory to Clinics. Mol Cancer Ther. 2016; 15(7): 1427-1435, doi: 10.1158/1535-7163.MCT15-0897, indexed in Pubmed: 27330107.

48. Lu LY, Yu X. The balance of Polo-like kinase 1 in tumorigenesis. Cell Div. 2009; 4: 4, doi: 10.1186/1747-1028-4-4, indexed in Pubmed: 19161615.

49. Lu LY, Wood JL, Minter-Dykhouse K, et al. Polo-like kinase 1 is essential for early embryonic development and tumor suppression. Mol Cell Biol. 2008; 28(22): 6870-6876, doi: 10.1128/ MCB.00392-08, indexed in Pubmed: 18794363.

50. Wierer M, Verde G, Pisano P, et al. PLK1 signaling in breast cancer cells cooperates with estrogen receptor-dependent gene transcription. Cell Rep. 2013; 3(6): 2021-2032, doi: 10.1016/j.celrep.2013.05.024, indexed in Pubmed: 23770244.

51. de Cárcer G, Venkateswaran SV, Salgueiro L, et al. Plk1 overexpression induces chromosomal instability and suppresses tumor development. Nat Commun. 2018; 9(1): 3012, doi: 10.1038/s41467-018-05429-5, indexed in Pubmed: 30069007.

52. Raab M, Sanhaji M, Matthess Y, et al. PLK1 has tumor-suppressive potential in APC-truncated colon cancer cells. Nat
Commun. 2018; 9(1): 1106, doi: 10.1038/s41467-018-03494-4, indexed in Pubmed: 29549256.

53. The Cancer Genome Atlas Program, https://www.cancer.gov/ about-nci/organization/ccg/research/structural-genomics/tcga (accessed 1 February 2020).

54. Györffy B, Lanczky A, Eklund AC, et al. An online survival analysis tool to rapidly assess the effect of 22,277 genes on breast cancer prognosis using microarray data of 1,809 patients. Breast Cancer Res Treat. 2010; 123(3): 725-731, doi: 10.1007/s10549-009-0674-9, indexed in Pubmed: 20020197.

55. The Kaplan Meier plotter, www.kmplot.com (accessed 1 February 2020).

56. Jalili A, Moser A, Pashenkov M, et al. Polo-like kinase 1 is a potential therapeutic target in human melanoma. J Invest Dermatol. 2011; 131(9): 1886-1895, doi: 10.1038/jid.2011.136, indexed in Pubmed: 21654832.

57. Zhang Z, Zhang G, Gao Z, et al. Comprehensive analysis of differentially expressed genes associated with PLK1 in bladder cancer. BMC Cancer. 2017; 17(1): 861, doi: 10.1186/s12885017-3884-2, indexed in Pubmed: 29246203.

58. Chen $\mathrm{J}, \mathrm{Wu} \mathrm{F}$, Shi $\mathrm{Yu}$, et al. Identification of key candidate genes involved in melanoma metastasis. Mol Med Rep. 2019; 20(2): 903-914, doi: 10.3892/mmr.2019.10314, indexed in Pubmed: 31173190 .

59. Schmit TL, Zhong W, Setaluri V, et al. Targeted depletion of Polo-like kinase (Plk) 1 through lentiviral shRNA or a small-molecule inhibitor causes mitotic catastrophe and induction of apoptosis in human melanoma cells. J Invest Dermatol. 2009; 129(12): 2843-2853, doi: 10.1038/jid.2009.172, indexed in Pubmed: 19554017.

60. Posch C, Cholewa BD, Vujic I, et al. Combined Inhibition of MEK and Plk1 Has Synergistic Antitumor Activity in NRAS Mutant Melanoma. J Invest Dermatol. 2015; 135(10): 2475-2483, doi: 10.1038/jid.2015.198, indexed in Pubmed: 26016894.

61. Chen HY, Villanueva J. Playing Polo-Like Kinase in NRAS-Mutant Melanoma. J Invest Dermatol. 2015; 135(10): 2352-2355, doi: 10.1038/jid.2015.253, indexed in Pubmed: 26358384.

62. Basile MS, Mazzon E, Fagone P, et al. Immunobiology of Uveal Melanoma: State of the Art and Therapeutic Targets. Front Oncol. 2019; 9: 1145, doi: 10.3389/fonc.2019.01145, indexed in Pubmed: 31750244.

Submitted: 12 March, 2020

Accepted after reviews: 22 June, 2020 Available as AoP: 30 June, 2020 